Article

\title{
Spatiotemporal Fragmentation of Urban Residential Land Use: A Case Study from China
}

\author{
Xue Liu ${ }^{1,2}$, Helin Liu ${ }^{3}$, Wanzhen Chen ${ }^{4, *}$ and Zhonghao Zhang ${ }^{5}$ \\ 1 School of Geographic and Oceanographic Sciences, Nanjing University, Nanjing 210023, China; \\ liuxue1222@ntu.edu.cn \\ 2 School of Civil Engineering and Architecture, Nantong University, Nantong 226019, China \\ 3 School of Architecture and Urban Planning, Huazhong University of Science and Technology, \\ Wuhan 430074, China; hl362@hust.edu.cn \\ 4 Department of Social Work, East China University of Science and Technology, Shanghai 200237, China \\ 5 Institute of Urban Studies, Shanghai Normal University, Shanghai 200234, China; zzh87@shnu.edu.cn \\ * Correspondence: cwzdyzj@126.com; Tel.: +86-21-6425-2413
}

Received: 23 March 2017; Accepted: 19 June 2017; Published: 23 June 2017

\begin{abstract}
Given the scarcity of land resources in most Chinese cities, the fragmentation of construction land use is a greater constraint than expansion for urban sustainability. Therefore, there is an urgent need to quantify the fragmentation level of construction land use for planning and managing practices. This study focuses on residential land use, which is one of the most important types of construction land use within built-up urban areas. Based on land use maps of the built-up areas, derived from master plans between 1994 and 2015, multi-spatiotemporal patterns of residential land use fragmentation are classified through a case study of Nantong, a rapidly urbanizing and industrializing city. The results show that the fragmentation of residential land use presented a slight descending trend from 1994 to 2002, and a sharp ascending trend from 2003 to 2015. Moreover, residential land use fragmentation in newly established zones witnessed the highest increase in fragmentation. Additionally, the analysis reveals that the fragmentation of residential land use reflects distinct variations across different urbanization stages, and the fragmentation level of residential land use is related to development density in Nantong city. Finally, socio-economic data was used to provide a quantitative insight into exploring the driving forces through multivariate linear regression. The results show that, triggered by land market reform, residential land use fragmentation in Nantong was mainly due to the rapid growth of the tertiary industry, and government policies.
\end{abstract}

Keywords: residential land use fragmentation; landscape metrics; driving forces; urbanization; Nantong

\section{Introduction}

China has experienced fast urbanization over the past three decades. Growth in the economy was steady due to reform and policies designed to open the economy, as well as globalization. Additionally, China experienced an explosive population increase in urban areas. The urbanization rate increased from $17.6 \%$ in 1978 to $56.1 \%$ in 2015 [1]. An increasing population and urbanization resulted in a rising demand for housing. As a consequence of reformations to the land and housing system since the 1990s, aggressive, large-scale, low-density, and non-continuous development of housing real estate was widely implemented in urban fringes and suburbs [2-4]. It led directly to a high level of residential land use fragmentation (defined as continuous areas of residential landscape changed into smaller, more isolated patches), characterized by irregular patch shapes, varying patch sizes, and dispersed arrangement between patches [5]. 
Land use fragmentation has been one of the most noticeable problems in the accelerated urbanization context of China. Before the 1980s, almost all urban land was administratively controlled and operated by the central government, and the transfer of urban land was prohibited [6]. Early in this period, residential estates were commonly built and organized in the form of "Dan wei", and primarily concentrated in the urban centers. Later, as the open market for urban land was established [3], local governments could earn large revenues from selling land to investors for large-scale real estate projects at the urban fringes and suburbs, causing severe landscape fragmentation. As a result, a series of negative effects on urban development associated with land use fragmentation emerged, such as deteriorated ecosystems [7-10] and low efficiency of land use [9-11]. In recent years, scholars have extensively discussed the phenomenon in which land use fragmentation in urban areas is posing pressing challenges in societies that use land-planning [11,12].

Most landscape fragmentation studies concentrate on patterns and dynamics analysis [10,13-18]. Landscape metrics, regarded as a common approach, are used to quantify landscape structures and patterns in the study of landscape ecology [19]. However, because they had the primary goal of identifying the composition patterns of different land use types within the ecological landscape, these studies tended to treat built-up areas as a single homogeneous element, along with other elements, such as farmland [20-22], forest [23,24], and green space [25]. Thus, residential land use, as a component of urban built-up areas, was rarely discussed from the perspective of fragmentation. In fact, residential land accounts for a large proportion of urban expansion, and is the leading component in the expansion and change of urban built-up areas [11], whose fragmentation level is closely related to compact urban development.

This paper examines the fragmentation of residential land use and the underlying mechanisms within the urban built-up area of Nantong city in the Yangtze River Delta region, using a multi-spatiotemporal perspective with the aim to provide the aforementioned missing information, and provide implications and suggestions for the improvement of residential land use planning in response to rapid urbanization. Based on residential land use data derived from a series of land use maps of the built-up area from 1994 to 2015, the spatiotemporal patterns of residential land use change and its dynamics were quantified using landscape metrics and multivariate linear regression. Through this approach, we aim to discover whether there are general trends of residential-land fragmentation corresponding to urbanization, analyze the fragmentation pattern and the driving forces behind it, and provide decision support for residential land use planning and managing practices.

The rest of the study is organized as follows: Section 2 describes the study area, and the source and processing of data. Section 3 illustrates the results of landscape pattern analysis and regression analysis. Section 4 discusses the spatiotemporal patterns and dynamics of residential land use fragmentation and provides policy implications. Section 5 draws conclusions based on the results and discussion.

\section{Methods and Data}

\subsection{Study Area}

Nantong is situated in the southeast part of the Jiangsu province, and adjacent to its south is Shanghai, the largest city and economic center in China. This particular location has profoundly contributed to making great achievements in urbanization and industrialization over the past 30 years. In 2015, Nantong's GDP was 6148.4 billion Yuan and the urbanization rate was 61.1\% [26], indicating its entry into the high-speed urbanization stage. Moreover, real estate investment amounted to 690.94 billion Yuan in 2015, and property sales totaled 937.96 million square meters [26], much higher than the average level in Jiangsu Province [27]. The real estate industry had become one of the strongest industries in Nantong, which resulted in the rising fragmentation level of residential land use in the suburbs and rural areas [28]. Inevitably, this fragmentation process led to Nantong having to confront commonly observed land use problems, such as land waste, increasing operation costs of public facilities, and deterioration of the ecological environment. As a city with high residential land 
fragmentation pushed forward by rapid urbanization and the socio-economic influence from a global city (Shanghai) [29], Nantong offers a typical setting in which to observe fragmentation patterns and their underlying mechanisms, which can serve as a reference for cities in similar contexts to slow or even solve the residential land use fragmentation problem.

The study area, located in the southwest of Nantong, is the built-up central urban area of the city prefectures. It includes three administrative districts: the urban center Chongchuan District (CD), the urban fringe Gangzha District (GD), and the Economic and Technological Development Zone (DZ), which is the new urban district. All parts together cover 418.03 square kilometers and have a population of 1.2 million [26] (Figure 1).
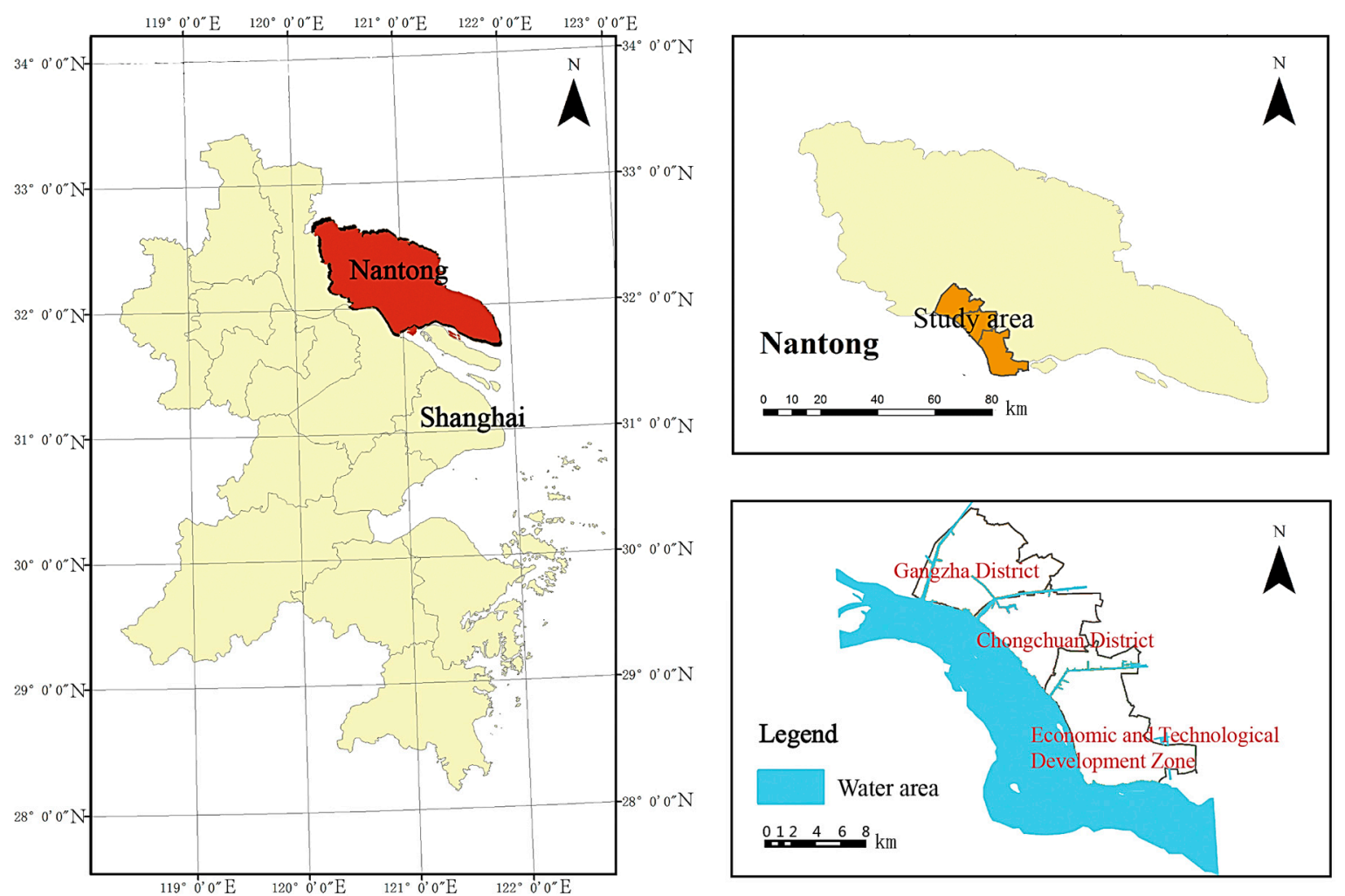

Figure 1. Location of Nantong and the study area, and distribution of the three districts within it.

\subsection{Data Source and Processing}

Remote sensing data has been widely used as data sources for studies in landscape ecology and land management disciplines. However, it is difficult to classify the various types of construction land within a built-up area. Compared with this, land use maps of built-up areas in this study are derived from historical land use data and careful fieldwork surveys in Nantong, and master plans are more detailed. These maps have details of the composition and distribution of eight sub-types of urban construction land, with three primary types: residential, commercial, and industrial land (GB50137-2011). More importantly, residential land use data that comes from the basic data of master plans matches well with the statistical socio-economic data that we used in the dynamic analysis.

In general, master plans need to be modified, accompanied by the process of urbanization and urban socio-economic development. Since the 1990s, the master plan of Nantong has been revised five times. Thus, the time sections covered in this paper correspondingly include the five specific years (1994, 2002, 2006, 2013, and 2015) when the master plan was revised. Residential land use mainly refers to residential areas and clusters of residential settlements (GB50137-2011). The spatial information on residential land use in Nantong was acquired, sorted, and tentatively explored. This contributed to the creation of the land use database of the three districts (CD, GD, and DZ). Because the 
data was vector-formatted, we then converted it to raster data with a $10 \mathrm{~m} \times 10 \mathrm{~m}$ spatial resolution using ArcGIS 10.0 [30]. When this process was complete, landscape metrics were calculated with Fragstats 4.2 [31], a widely used landscape analysis package. Throughout the analysis, we also used socio-economic data from 1994, 2002, 2006, 2013, and 2015 (see Section 2.4 for more details), which was obtained from the Nantong Municipal Bureau of Statistics.

\subsection{Landscape Metrics}

Originally developed in the study of landscape ecology, landscape metrics have been recently applied to research on the internal structure of construction land, which is usually regarded as a homogeneous component [11]. Landscape metrics have been developed to describe the types, numbers, spatial distribution, and configuration of various landscape components [19]. In this context, the internal structure is still quantified by measures derived from landscape metrics. Following this line, four landscape metrics are applied in this study to describe residential land use patterns, which then serve as an indicator of the fragmentation level. The metrics are as follows: percentage of landscape (PLAND), patch density (PD), landscape shape index (LSI), and patch cohesion index (COHE). The definition of each metric is detailed in Table 1. The reason why these four landscape metrics (PLAND, PD, LSI and COHE) are adopted is to reduce redundancy and correlation so that the overall features can be captured. For each of the five years, the value of all four landscape metrics was calculated with FRAGSTAT 4.2 [31].

Table 1. Associations between landscape metrics and residential fragmentation.

\begin{tabular}{ccc}
\hline $\begin{array}{c}\text { Metrics } \\
\text { (Abbreviation) }\end{array}$ & Formula and Description & Range \\
\hline $\begin{array}{c}\text { Percentage of } \\
\text { landscape (PLAND) }\end{array}$ & $\begin{array}{c}\text { PLAND }=\sum_{j=1}^{n} a_{i j} / A \\
\text { PLAND equals the proportion of total residential area. } \\
\text { It measures the size of a residential area }\end{array}$ & $0 \leq$ PLAND $\leq 100$ \\
\hline $\begin{array}{c}\text { PD }=n_{i} / A \\
\text { Patch density (PD) }\end{array}$ & $\begin{array}{c}\text { PD equals the number of residential land use patches per } \\
\text { area. It measures residential land use fragmentation }\end{array}$ & PD > 0, without limit \\
\hline $\begin{array}{c}\text { Landscape shape } e_{i} / \text { mine } e_{i} \\
\text { index (LSI) }\end{array}$ & $\begin{array}{c}\text { LSI equals edge density adjusted for size of the } \\
\text { landscape. It is a measure of residential land use patch } \\
\text { shape complexity }\end{array}$ & LSI $\geq 1$, without limit \\
\hline $\begin{array}{c}\text { Patch cohesion } \\
\text { index (COHE) }\end{array}$ & $\begin{array}{c}\text { COHE }=\left[1-\sum_{j=1}^{n} p_{i j} / \sum_{j=1}^{n} p_{i j} \sqrt{a_{i j}}\right][1-1 / \sqrt{N}]^{-1} \\
\text { COHE equals the aggregation or clumping of cover } \\
\text { types into patches. It is a measure of the physical } \\
\text { connectedness of residential land use patches }\end{array}$ & $0 \leq$ COHE $\leq 100$ \\
\hline
\end{tabular}

\subsection{Variables to Describe the Potential Driving Forces}

Previous studies on land use fragmentation have indicated that the driving forces of this process should be understood in the context of specific geographical, socioeconomic, and political systems $[12,15]$. Therefore, the potential driving forces considered in this study are divided into three components, including socio-economic factors, government regulations, and globalization forces (Table 2). First, as the economic growth of China over the past 30 years was primarily based on the extensive management of land and production resources, the increased GDP was, to some extent, an indication of land expansion. Additionally, with rapid population growth, more goods would be needed, and a large amount of land in Nantong would be invested in for residential use. Therefore, gross domestic product (GDP) and total retail sales of social consumer goods (SCG) were selected to represent the driving forces of the socio-economic system. Second, investment in fixed assets (IFA) and the added value of tertiary/secondary industry (ATI) were used to describe the impact of government 
regulation. Due to the specific institutional context and land use right system in China, Chinese local government plays a leading role in urban economic growth and land use arrangement [32]. The local government tends to allocate more land to real estate development, constructing urban public facilities, and infrastructure, from which a large amount of revenue can be derived. The last aspect is globalization. As has been revealed, over the last 30 years, the economy of China, as well as urban development, has been profoundly influenced by globalization $[12,33,34]$. This is particularly the case in a global city such as Shanghai, and the cities and towns within the city-region where it is located. Because it is an important part of the Shanghai metropolis, which gives the location an advantage, for more than 30 years Nantong has been the destination for foreign developers to invest in urban real estate and industries, which has led to direct changes in residential landscapes. To reflect this impact caused by globalization, we used two variables: import-export value (IEV) and total foreign capital in actual use (TFU). Geographical factors were not taken into consideration in the management practices of this study, while the distribution of geographical elements is always emphasized when making land plans.

Table 2. Variables used to describe the potential driving forces of residential land use fragmentation.

\begin{tabular}{ccc}
\hline Dimension & Variable & Description \\
\hline \multirow{2}{*}{ Socio-economic } & Gross domestic product (GDP) & Total amount of economy \\
\cline { 2 - 3 } Governance & $\begin{array}{c}\text { Total retail sales of social consumer } \\
\text { goods (SCG) }\end{array}$ & $\begin{array}{c}\text { Total volume of domestic } \\
\text { consumption demand }\end{array}$ \\
\cline { 2 - 3 } & $\begin{array}{c}\text { Total investment in fixed assets (IFA) } \\
\text { value of secondary industry (ATI) }\end{array}$ & $\begin{array}{c}\text { Total volume of construction and } \\
\text { acquisition of fixed assets }\end{array}$ \\
\hline \multirow{2}{*}{ Globalization } & Import-export value (IEV) & tertiary and secondary industries \\
\cline { 2 - 3 } & Total foreign capital in actual use (TFU) & Total volume of foreign capital utilization \\
\hline
\end{tabular}

To distinguish the differences in the impacts of driving factors on residential land use fragmentation in Nantong, regression relationships are established between each landscape metric and potential driving factors by stepwise regression, using a multivariate linear regression model. All of the variables were standardized, and then they were entered and selected by the regression model in a stepwise manner. In the multivariate linear regression model, variables that have multicollinearity were filtered and removed using a stepwise regression. Following the stepwise regression, the independent variables that eventually remain in the model are important and exhibit low multicollinearity. Finally, the dependent variables are four landscape metrics (PLAND, PD, LSI and COHE), and the six predictor variables listed in Table 2 are the independent variables. We performed stepwise regression on landscape metrics and selected driving factors using SPSS 22.0 (International Business Machines Corporation (IBM), Armonk, MA, USA).

\subsection{Moving Window Analysis Approach}

To visualize the spatiotemporal evolution of residential land use fragmentation from an urban morphology perspective, a moving window analysis approach [35] was applied to calculate the spatial distribution of PD level in the study area (see Section 3.3 for more details) using ArcGIS 10.0 [30] and FRAGSTAT 4.2 [31]. To apply this method, a certain size of the analysis window must be defined. Then, from the upper left corner of the study area, we need to move the window, grid by grid, and calculate the fragmentation value of each window for each step. When the calculation was completed, we assigned this value to the central grid of the window, and thus obtain the raster map of the calculated landscape metric value. Preliminary experiments were conducted with given grid cell sizes, from $500 \mathrm{~m}, 1 \mathrm{~km}, 2 \mathrm{~km}, 3 \mathrm{~km} \ldots$, respectively, and finally the moving window of $1 \mathrm{~km} \times 1 \mathrm{~km}$ was proved to be the adaptive scale to examine the changes in the PD value in our analysis. 


\section{Results}

\subsection{The Expansion of Residential Land Use in Nantong City}

Residential land use expansion in Nantong is illustrated in Figure 2, which shows that residential land use experienced a remarkable increase over the past 20 years, from 1994 to 2015. PLAND increased from 2.06 in 1994 to 9.87 in 2015 at a rate of $379 \%$, indicating that residential land use had been expanding continually and dramatically, in parallel with rapid urbanization. In addition, PLAND also reveals the imbalance among the three districts. On the one hand, the value of PLAND in CD in each of the five years $(1994,2002,2006,2013$, and 2015) was the highest when compared with that in GD and the DZ. On the other hand, the expansion rate of residential land use was different among the three districts. PLAND rose from 6.23 in 1994 to 20.05 in 2015 in CD, from 1.32 to 8.12 in GD, and from 0.17 to 5.21 in the DZ. The value change rate of PLAND in the DZ was $2951 \%$, much greater than that in the other two districts over the study period. These results manifest that the expansion of residential land was encouraged in the newly established zones.
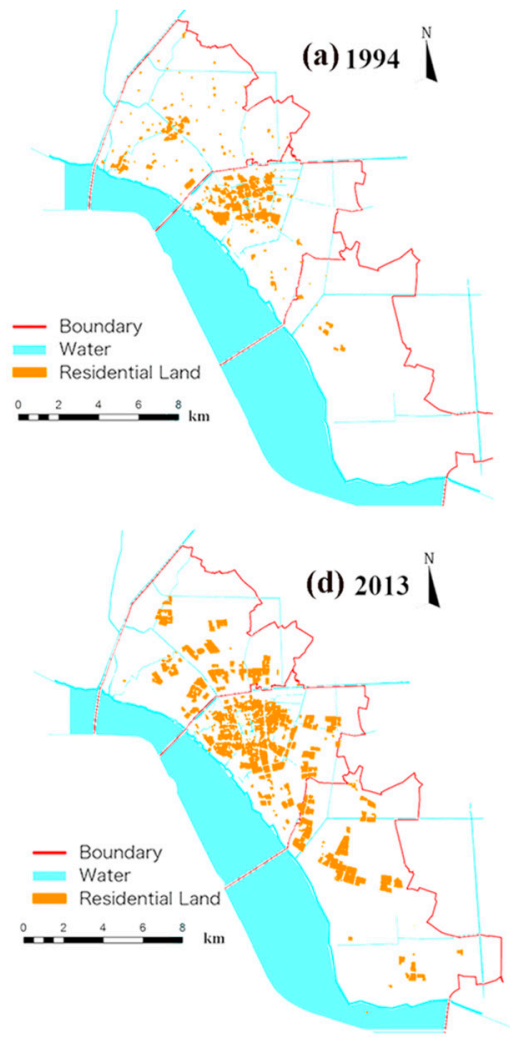
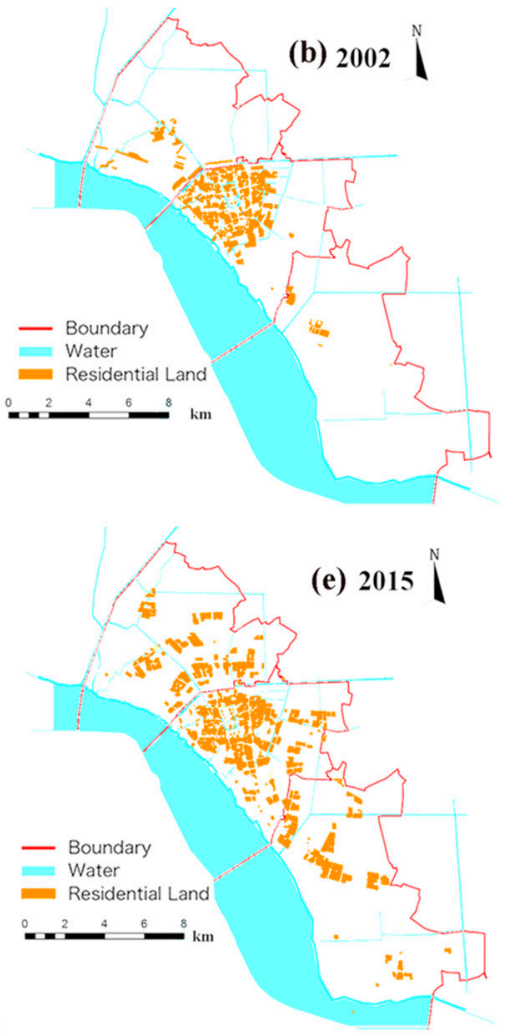
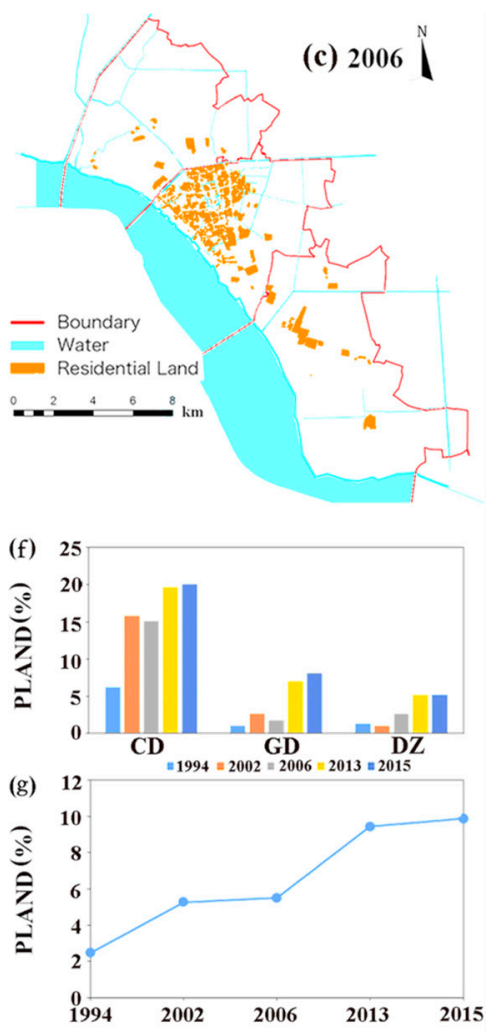

Figure 2. The changes in residential land use in Nantong city from 1994 to 2015. (a) 1994; (b) 2002; (c) 2006; (d) 2013; (e) 2015; (f) the changes in PLAND in CD, GD, and the DZ; (g) the changes in PLAND in all three districts. Abbreviation: the proportion of total residential area (PLAND).

\subsection{The Spatial Evolution of Residential Land Use Fragmentation}

Figure 3 shows the results of a metric analysis using different landscape metrics for both the whole city of Nantong, and its three districts. PD decreased slightly from 0.41 in 1994 to 0.40 in 2002, and then increased rapidly to 0.76 in 2015, indicating that Nantong's residential land use fragmentation presented a slight decrease from 1994 to 2002, and later an increase from 2003 to 2015. This finding reveals that Nantong's residential land use fragmentation intensified during the study period. LSI increased from 15.44 in 1994 to 27.48 in 2015, which denotes an increase in irregular and complex residential land use patch shapes. At the same time, COHE showed a descending 
tendency, which denotes that residential land use patches became dispersed from each other. Besides, a comparison of the results of PD in the three districts provided further insight into the process. The change rate of the PD value in CD was 34\%, much lower than $144 \%$ in GD and $530 \%$ in the DZ during the study period, indicating that the DZ had the greatest variation in the residential land use fragmentation rate.

PD (Ind/ha)
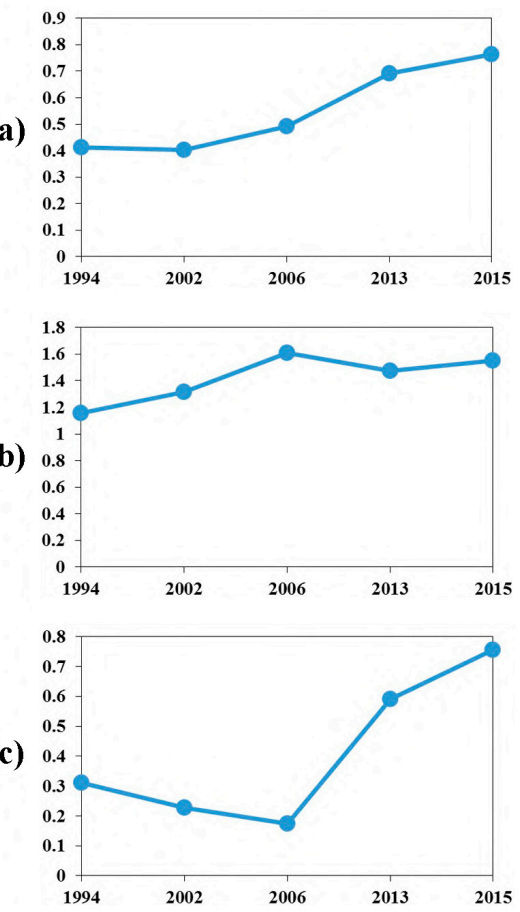

(d)

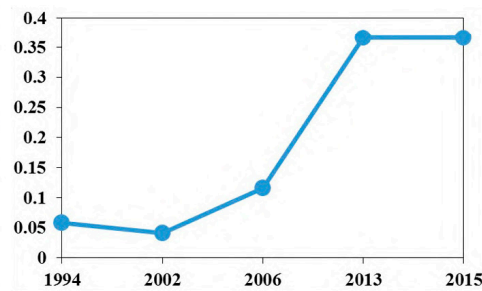

LSI $\left(\mathrm{m} / \mathrm{m}^{2}\right)$
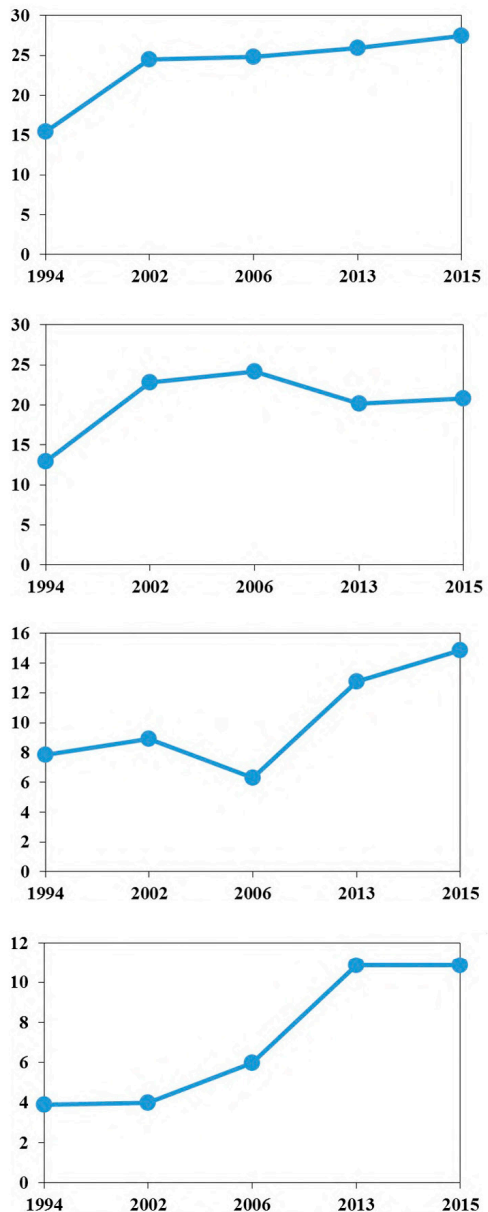

COHE $(\%)$
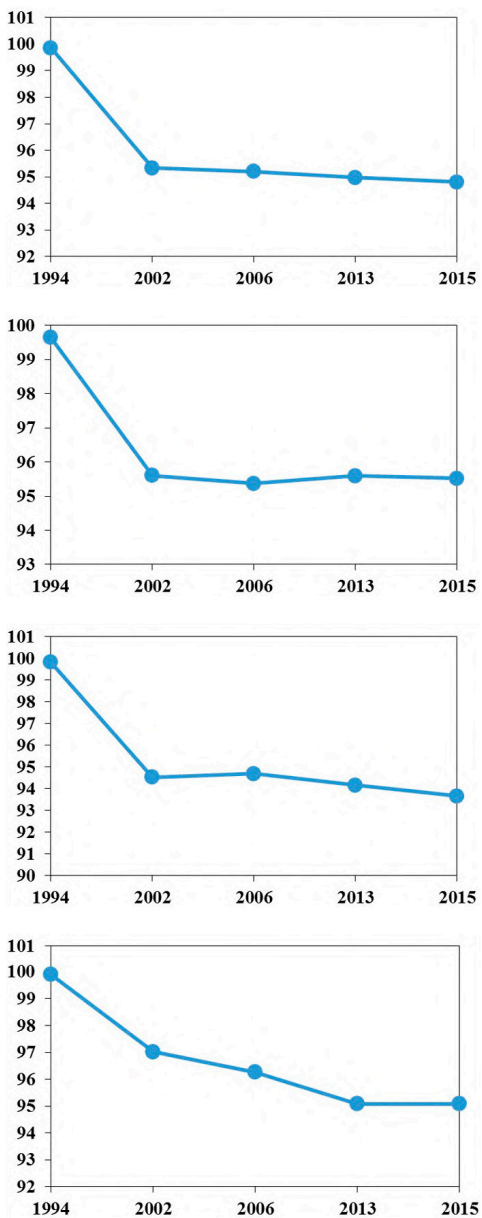

Figure 3. Temporal variation of three landscape metrics over 1994-2015 in (a) Nantong; (b) Chongchuan District (CD); (c) Gangzha District (GD); (d) Economic and Technological Development Zone (DZ). Abbreviations: patch density (PD), landscape shape index (LSI), patch cohesion index (COHE).

\subsection{The Evolution Characteristics of Residential Land Use Fragmentation from a City Morphology Perspective}

Examined from an urban morphology perspective $[15,35,36]$, residential land use fragmentation in CD was in a concentric ring from 1994 to 2006 (Figure 4a,b). Moreover, up to 2015, the ring had been reinforced, and resulted in a ripple effect traveling away from the ring to the suburban areas (Figure 4c). In addition, the fragmentation level was intensified by transportation corridors and several newly established zones located far away from Nantong city center, characterized as a polycentric pattern in 2015 (Figure 4c). 
(a) $1994 \overbrace{}^{N}$

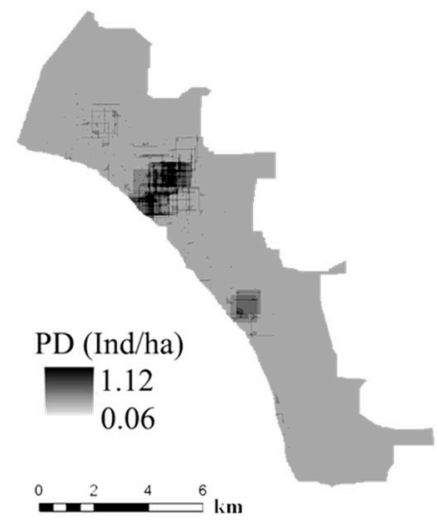

(b) 2006

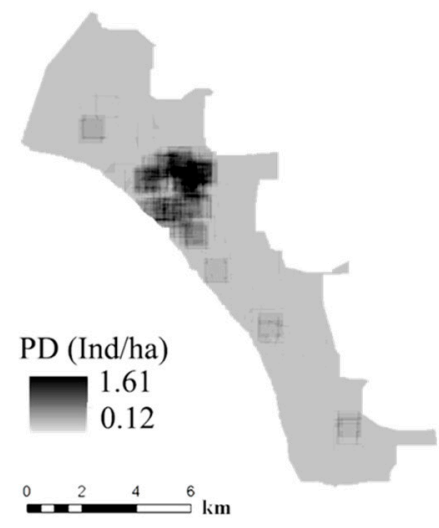

(c) 2015

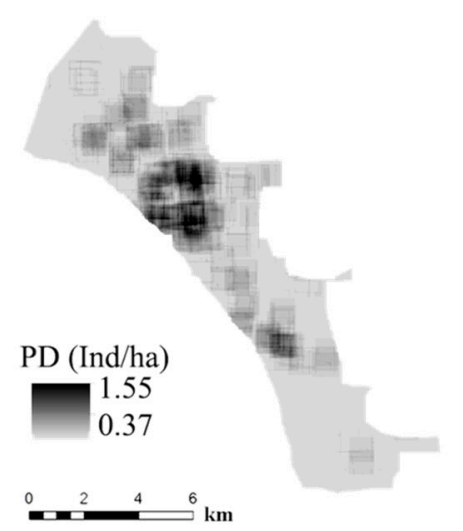

Figure 4. Spatial distribution of PD level in (a) 1994; (b) 2006; (c) 2015. Abbreviation: patch density (PD).

\subsection{Driving Forces of Residential Land Use Fragmentation in Nantong City}

Relationships between residential land use fragmentation and potential influencing factors are shown in Table 3. The importance and effect of explanatory indicators varied with different landscape metrics. ATI had a positive relationship with PD. From 1994 to 2015, the percentage of GDP from the tertiary industry underwent increasing growth. It denotes that the comparatively rapid growth of the tertiary industry significantly increased the fragmentation of residential land use with ongoing urbanization. For PLAND, ATI was also a positive variable, manifesting that economic development driven by the tertiary industry was the core force leading to the expansion of residential land use. Compared with PD and PLAND, LSI was driven more by ATI and TFU. Both of them had positive impacts on the shape of residential land use patches. It implies that the growth of the tertiary industry and foreign capital increased the complexity of the shape of residential land use patches. ATI had a negative effect on $\mathrm{COHE}$, indicating that the growth of the tertiary industry could make residential land patches more dispersed.

Table 3. Relationships between landscape metrics and selected variables.

\begin{tabular}{cc}
\hline Regression & Adjust $R^{2}$ \\
\hline PD $=0.22+1.37 \times$ ATI & $0.77^{* * *}$ \\
LSI $=0.37+1.08 \times$ ATI $+0.42 \times$ TFU & $0.72^{* * *}$ \\
COHE $=-0.01-0.95 \times$ ATI & $0.74^{* * *}$ \\
PLAND $=0.29+1.38 \times$ ATI & $0.83^{* * *}$
\end{tabular}

*** $p<0.001$. Abbreviations: patch density (PD), landscape shape index (LSI), patch cohesion index (COHE), percentage of landscape (PLAND), added value of tertiary industry/added value of secondary industry (ATI; \%), total foreign capital in actual use (TFU; billion US Dollars).

\section{Discussion}

\subsection{The Relationship between the Fragmentation of Residential Land Use and Urbanization}

The fragmentation of Nantong's residential land use has progressed in phases, with fluctuations occurring in line with different stages of urbanization, in keeping with the findings of Weng [10] and Herold et al. [37]. Generally, this study found that the percentage of residential land increases as urbanization proceeds, as well as the level of fragmentation in the use of this land. However, the rate of residential land use fragmentation was found to vary in relation to urbanization $[10,32,38]$. At the beginning of the latter, residential development concentrated around the urban center due to an agglomeration effect [39]. When urbanization slowed down, the fragmentation level of land use in the 
urban center stabilized due to limited space available for residential use and the high cost of land [40]. In contrast, newly established zones presented the most intense increase of residential land use fragmentation due to their low-cost land, incentivizing policies, and a lack of systematic planning [41]. When responding to the implications of these findings, planners and decision makers must decide in which phase of urbanization a particular land case is situated, and identify the residential land development mode and location preference.

\subsection{The Spatial Characteristics of Residential Land Use Fragmentation}

The result that the newly established zones presented the fastest increase in residential land use fragmentation in Nantong from 1994 to 2015 was inconsistent with Weng [10], who stated that residential land fragmentation was most severe in the urban fringes. This may have been caused by the massive development of newly established zones, driven by the land finance of Chinese local governments, which is different to the finance mechanisms provided by Western countries [3,39]. In fact, two general trends of fragmentation change reported by former studies and discussions $[10,11,14]$ are also supported in this study. First, a scattered form of residential development with low density in newly established zones will result in more fragmentation. Second, a compact form of residential development with high density in the urban center will decrease its fragmentation $[2,15]$. In light of these findings, it is recommended that planners coordinate different mechanisms in the center and the suburbs during the planning phase, in order to construct specific policy frameworks that are tailored to the needs of different areas.

\subsection{The Dynamic Mechanisms of Residential Land Use Fragmentation in Nantong}

China's economic development, which has been particularly driven by the tertiary industry, has played a key role in increasing the fragmentation of Nantong's residential land. This finding echoes that of Zhang [42], who stated that the improvement of social and economic conditions in a community has prominent impacts on the distribution patterns of real estate developments. In the context of socio-economic transition, Nantong's residential development is also closely linked to the dynamics of the land market and local governments' land planning policies [43]. In the early period of China's market-oriented reform [44], economic growth and people's desire to attain better living conditions were the driving force behind investment in housing estates [45]. Since 2003, Nantong has experienced a boom in its housing estate market [3] and an unprecedented scale of housing development in newly established zones. However, as the city's land supply system has been quasi-market oriented [46], and a comprehensive legal plan always lagged behind the construction projects, this generally resulted in a disorderly distribution of residential land, especially in newly established zones. Recently, China's central government issued a series of stringent control policies for the real estate industry [16,40], and local governments began to change their traditional economic growth mode [46], which primarily relied on land sales and massive construction, leading to the steady development of housing. These changes demonstrate that changing policies have also played important roles in the fragmentation of Nantong's residential land use. In addition, the foreign capital investment in the construction of Nantong has significant effects on the fragmentation of residential land. However, most of Nantong's residential development projects have typically been located in the newly established zones, presenting a scattered distribution and leading to an increase in the irregularity of the city's land use.

\subsection{Application to Urban Residential Land Use}

Due to an increasing population and scarcity of land resources, the fragmentation of residential land use has always been a complex problem [11]. The application of metric analysis can help planners to prepare strategies to respond by identifying potential fragmentation of residential land use. In practice, landscape metrics provide planners with a convenient and helpful tool to assess residential development [11]. In the following, relevant policy implications are discussed regarding different geographical locations and different stages of urbanization. 
First, to reduce the over-consumption of land, planners and decision-makers should pay more attention to the density and intensity of transformation from non-construction land to residential land [10]. Due to the more market-oriented land supply system [46], local governments tended to abuse their monopoly on land resources to obtain a high land premium [16], leading to low density residential developments in newly established zones. Against this background, the central government completed a series of farmland protection policies and legislation, but they did not effectively prevent the over-consumption of farmland [32,40]. In this situation, strict policies should be introduced, such as urban growth boundaries (UGBs) [47] and high-density development [10], to reduce the residential development that has dispersed and low-density patterns.

Second, more rigorous management policies should be issued to confront the problem of residential land use fragmentation in newly established zones. There were several reasons for local governments and developers to be in favor of residential projects in newly established zones. On the supply side, due to low land acquisition and development costs [41], local governments and developers were interested in residential projects that were located in newly established zones [12]. On the demand side, local residents were likely to choose houses in newly established zones that had low prices and high-quality living environments. In addition, the enforcement of the strategy of polycentric development, primarily by means of the development of newly established zones [3], was significant. Consequently, residential development, characterized by large-scale projects, with a form of dispersed and low density development, was characteristic of the newly established zones [16,41]. These results demand rigorous management policies, such as developing an overall plan for residential land each year, and regulating the leasing and development density of residential land [3,11,40].

Third, different management policies should be issued, aimed at different stages of urbanization [38,39]. As urbanization proceeds, urban centers become stable, and at the same time, newly established zone development usually consumes a large amount of residential land but accommodates a low population density [3], causing severe residential land use fragmentation. This situation can be improved if local governments intensify space economics and functional relationships between the urban center and the newly established zones, through the development of adequate infrastructural facilities and more job opportunities in newly established zones.

\section{Conclusions}

This paper explored the spatiotemporal changes in landscape patterns in residential land use, and offered quantitative insights into exploring the dynamic mechanisms of residential land fragmentation in Nantong city with its rapid urbanization from 1994 to 2015. In light of the compact development goal and the increasingly strict control of urban land expansion, this paper can be regarded as a timely assessment of residential land use fragmentation, and can be applied as guidance for residential land use planning and management practices. We used landscape metrics to analyze the residential land use data derived from Nantong's land use maps, and applied multivariate linear regression to quantitatively explore the driving factors behind the process of Nantong's residential land use fragmentation. We found that Nantong has experienced rapid residential land expansion and spatial imbalance among the three districts by referring to the values of PLAND from 1994 to 2015.

Metric analysis has quantified the spatiotemporal features of residential land use fragmentation in Nantong. The results reveal distinct temporal fluctuation and spatial differentiation in Nantong's residential land use fragmentation. On the one hand, there is a close relationship between fragmentation level and urbanization stages. On the other hand, two general trends of spatial changes in residential land use fragmentation were found: a scattered form of residential development with a low density in the newly established zones will lead to the increase of fragmentation, and a contiguous form of residential development with a high density in the urban center can decrease fragmentation.

The results of the regression analysis revealed that the rapid increase in the tertiary industry had the most noticeable impacts on residential land use fragmentation in Nantong. In the context of 
socio-economic transition, Nantong's residential land use fragmentation is also closely related to the dynamics of the land market and government policies.

With the orientation of compact land use in China, "compact city" will be the future mode of Chinese city development [11], which means that consolidating fragmented construction land patches in the core areas and increasing the development density, as well as optimizing the various types of construction land use, especially residential land use, is crucial. In this sense, fragmentation metrics can be used as good planning assessment tools to provide a timely, ecologically oriented approach to assess construction land use. Furthermore, this approach has the advantage of matching the fragmentation level to the administrative territories. Thus, socio-economic data and governance bodies can be linked directly and clearly to explore the driving factors underlying it, which is more constructive when developing more accustomed local planning and management policies.

Acknowledgments: The research was funded by The Recruitment Program of Global Experts (Youth Group) of China (Grant No. D1218006), the Fundamental Research Funds for the Central Universities from ECUST (WE1524308), the Independent Research Grant from HUST (Grant No. 2015MS106), Chinese National Natural Science Foundation (Grant No. 41601139), Jiangsu Province Natural Science Foundation (SJ216065), and Chinese National Social Science Foundation (Grant No.16BGL214).

Author Contributions: Xue Liu and Wanzhen Chen conceived and designed the experiments. Xue Liu and Helin Liu analyzed the data and wrote the manuscript. Wanzhen Chen and Zhonghao Zhang helped improve the manuscript. All authors have read and approved the final manuscript.

Conflicts of Interest: The authors declare no conflict of interest.

\section{References}

1. National Bureau of Statistics of China (NBSC). China Statistical Yearbook; China Statistics Press: Beijing, China, 2014.

2. Shrestha, M.K.; York, A.M.; Boone, C.G. Land fragmentation due to rapid urbanization in the Phoenix Metropolitan Area: Analyzing the spatiotemporal patterns and drivers. Appl. Geogr. 2012, 2, 522-531. [CrossRef]

3. Liu, Y.; Yue, W.; Fan, P. Suburban residential development in the era of market-oriented land reform: The case of Hangzhou, China. Land Use Policy 2015, 42, 233-243. [CrossRef]

4. Li, T. Land use dynamics driven by rural industrialization and land finance in the peri-urban areas of China: "The examples of Jiangyin and Shunde". Land Use Policy 2015, 45, 117-127.

5. Jabareen, Y.R. Sustainable urban forms: Their typologies, models, and concepts. J. Plan. Educ. Res. 2006, 26, 38-52. [CrossRef]

6. Xie, Q.; Parsa, A.R.G.; Redding, B. The emergence of the urban land market in China: Evolution, structure, constraints and perspectives. Urban Stud. 2002, 39, 1375-1398. [CrossRef]

7. Saunders, D.A.; Hobbs, R.J.; Margules, C.R. Biological consequences of ecosystem fragmentation: A review. Conserv. Biol. 1991, 5, 18-32. [CrossRef]

8. Carsjens, G.J.; van Lier, H.N. Fragmentation and land-use planning-An introduction. Landsc. Urban Plan. 2002, 28, 79-82. [CrossRef]

9. Fahrig, L. Effects of habitat fragmentation on biodiversity. Annu. Rev. Ecol. Evol. Syst. 2003, 34, 487-515. [CrossRef]

10. Weng, Y.-C. Satiotemporal changes of landscape pattern in response to urbanization. Landsc. Urban Plan. 2007, 81, 341-353. [CrossRef]

11. Wei, Y.P.; Zhang, Z.Y. Assessing the fragmentation of construction land in urban areas: An index method and case study in Shunde, China. Land Use Policy 2012, 29, 417-428. [CrossRef]

12. You, H.Y. Quantifying urban fragmentation under economic transition in Shanghai city, China. Sustainability 2016, 8, 21. [CrossRef]

13. Tan, S.H.; Heerink, N.; Qu, F.T. Land fragmentation and its driving forces in China. Land Use Policy 2006, 23, 272-285. [CrossRef]

14. Yu, X.J.; Ng, C.N. Spatial and temporal dunamics of urban sprawl along two urban-rural transects: A case study of Guangzhou, China. Landsc. Urban Plan. 2007, 79, 96-109. [CrossRef] 
15. York, A.M.; Shrestha, M.K.; Boone, C.G.; Zhang, S.; Harrington, J.A.; Prebyl, T.J.; Swann, A.; Agar, M.; Antolin, M.F.; Nolen, B.; et al. Land fragmentation under rapid urbanization: A cross-site analysis of Southwestern cities. Urban Ecosyst. 2011, 14, 429-455. [CrossRef]

16. Feng, L.; Li, H. Spatial pattern analysis of urban sprawl: Case study of Jiangning, Nanjing, China. J. Urban Plan. Dev. 2012, 138, 263-269. [CrossRef]

17. Inostroza, L.; Baur, R.; Csaplovics, E. Urban sprawl and fragmentation in Latin America: A dynamic quantification and characterization of spatial patterns. J. Environ. Manag. 2013, 115, 87-97. [CrossRef] [PubMed]

18. Zhang, Z.H.; Tu, Y.J.; Li, X. Quantifying the spatiotemporal patterns of urbanization along urban-rural gradient with a roadscape transect approach: A case study in Shanghai, China. Sustainability 2016, 8, 862. [CrossRef]

19. Gustafson, E. Quantifying landsacpe spatial pattern: What is the state of the art? Ecosystems 1998, 2, 143-156. [CrossRef]

20. Su, S.; Jiang, Z.; Zhang, Q.; Zhang, Y. Transformation of agricultural landscapes under rapid urbanization: A threat to sustainability in Hang-Jia-Hu region, China. Appl. Geogr. 2011, 31, 439-449. [CrossRef]

21. Su, S.; Wang, Y.; Luo, F.; Mai, G.; Pu, J. Peri-urban vegetated landscape pattern changes in relation to socioeconomic development. Ecol. Indic. 2014, 46, 477-486. [CrossRef]

22. Chen, J.; Chang, K.; Karacsonyi, D.; Zhang, X. Comparing urban land expansion and its driving factors in Shenzhen and Dongguan, China. Habitat Int. 2014, 43, 61-71. [CrossRef]

23. Gibbs, J.P. Distribution of woodland amphibians along a forest fragmentation gradient. Landsc. Ecol. 1998, 13, 263-268. [CrossRef]

24. Abdullah, S.A.; Nakagoshi, N. Forest fragmentation and its correlation to human land use change in the state of Selangor, Peninsular Malaysia. For. Ecol. Manag. 2007, 241, 39-48. [CrossRef]

25. Tian, Y.; Jim, C.Y.; Tao, Y.; Shi, T. Landscape ecological assessment of green space fragmentation in Hong Kong. Urban For. Urban Green. 2011, 10, 79-86. [CrossRef]

26. Nantong Statistical Bureau. Nantong Statistical Yearbook; China Statistics Press: Beijing, China, $1994-2015$.

27. Jiangsu Bureau of Statistics of China (NBSC). China Statistical Yearbook; China Statistics Press: Beijing, China, 2015.

28. Fangfang, C.; Lijie, P.; Ming, Z. Assessment framework and decision-Support System for consolidating urban-rural construction land in coastal China. Sustainability 2014, 6, 7689-7709.

29. Tian, G.; Jiang, J.; Yang, Z.; Zhang, Y. The urban growth, size distribution and spatio-temporal dynamic pattern of the Yangtze River Delta megalopolitan region, China. Ecol. Model. 2011, 222, 865-878. [CrossRef]

30. ESRI. Arcgis Desktop: Release 10; Environmental Systems Research Institute: Redlands, CA, USA, 2011.

31. McGarigal, K.; Marks, B.J. Spatial Pattern Analysis Program for Quantifying Landscape Structure; Genneral Technical Reporet PNW-GTR-351; US Department of Agriculture, Forest Service, Pacific Northwest Research Station: Portland, OR, USA, 1995.

32. Lu, S.S.; Guan, X.L.; He, C.; Zhang, J.L. Spatio-temporal patterns and policy implications of urban land expansion in metropolitan areas: A case study of Wuhan urban agglomeration, central China. Sustainability 2014, 6, 4723-4748. [CrossRef]

33. Qu, F.; Heerink, N.; Wang, W. Land administration reform in China: Its impact on land allocation and economic development. Land Use Policy 1995, 12, 193-203. [CrossRef]

34. Wei, Y.H.D.; Li, W.M. Reforms, globalization, and urban growth in China: The case of Hangzhou. Eurasian Geogr. Econ. 2002, 43, 459-475. [CrossRef]

35. Riitters, K.H.; Wickham, J.D.; O’Neill, R.V.; Jones, K.B.; Smith, E.R.; Coulston, J.W. Fragmentation of continental United States forests. Ecosystems 2002, 5, 815-822. [CrossRef]

36. Long, H.; Zou, J.; Pykett, J.; Li, Y. Analysis of rural transformation development in China since the turn of the new millennium. Appl. Geogr. 2011, 31, 1094-1105. [CrossRef]

37. Herold, M.; Scepan, J.; Clarke, K.C. The use of remote sensing and landscape metrics to describe structures and changes in urban land uses. Environ. Plan. A 2002, 34, 1443-1458. [CrossRef]

38. Wu, J.; Jenerette, G.D.; Buyantuyev, A.; Redman, C.L. Quantifying spatiotemporal patterns of urbanization: The case of the two fastest growing metropolitan regions in the United States. Ecol. Complex. 2011, 8, 1-8. [CrossRef] 
39. Liu, Z.F.; He, C.Y.; Wu, J.G. General spatiotemporal patterns of urbanization: An examination of 16 world cities. Sustainability 2016, 8, 41. [CrossRef]

40. Seto, K.C.; Fragkias, M. Quantifying spatiotemporal patterns of urban land-use change in four cities of China with time series landscape metrics. Landsc. Ecol. 2005, 20, 871-888. [CrossRef]

41. Feng, L.; Du, P.J.; Li, H.; Zhu, L.J. Measurement of urban fringe sprawl in Nanjing between 1984 and 2010 using multidimensional indicators. Geogr. Res. 2015, 53, 184-198. [CrossRef]

42. Zhang, T. Community features and urban sprawl: The case of the Chicago metropolitan region. Land Use Policy 2001, 18, 221-232. [CrossRef]

43. Liu, Y.; Yue, W.; Fan, P. Spatial determinants of urban land conversion in large Chinese cities: A case of Hangzhou. Environ. Plan. B Plan. Des. 2011, 38, 706-725. [CrossRef]

44. Zhou, Y.; Ma, L. Economic restructuring and suburbanization in China. Urban Geogr. 2000, 21, $205-236$. [CrossRef]

45. Yang, J.; Sun, J.; Zhao, H.D.; Xi, J.C.; Li, X.M. Spatio-temporal differentiation of residential land for coastal town: A case study of Dalian Jinshitan. Chin. Geogr. Sci. 2016, 26, 566-576. [CrossRef]

46. Feng, J.; Zhou, Y. Suburbanization and the changes of urban internal spatial structure in Hangzhou, China. Urban Geogr. 2005, 26, 107-136. [CrossRef]

47. Yue, W.Z.; Zhang, L.L.; Liu, Y. Measuring sprawl in large Chinese cities along the Yangtze River via combined single and multidimensional metrics. Habitat Int. 2016, 57, 43-52. [CrossRef]

(C) 2017 by the authors. Licensee MDPI, Basel, Switzerland. This article is an open access article distributed under the terms and conditions of the Creative Commons Attribution (CC BY) license (http://creativecommons.org/licenses/by/4.0/). 